\title{
OESTRUS AND INDUCED OVULATION IN MONTANE VOLES
}

\author{
G. D. GRAY, H. N. DAVIS, M. ZERYLNICK AND \\ D. A. DEWSBURY \\ Department of Psychology and Center for Neurobiological Sciences, \\ University of Florida, Gainesville, Florida 32611, U.S.A.
}

(Received 23rd October 1973)

\begin{abstract}
Summary. An investigation of the reproductive cycle of montane voles, Microtus montanus, in the laboratory gave three main findings. Firstly, this species showed a pattern of induced ovulation. Mated, oestrous females showed $100 \%$ ovulation while only two of twelve unmated, oestrous females ovulated. Secondly, there was an absence of regular oestrous cycles both when females were isolated or adjacent to males. Thirdly, there was evidence for the occurrence of a postpartum oestrous period during which fertile matings were possible. These results support the suggestion that induced ovulation and the absence of regular oestrous cycles may be characteristic of the reproductive biology of Microtus.
\end{abstract}

Several species of the rodent genus Microtus are known to exhibit induced ovulation with an absence of regular oestrous cycles (Bodenheimer \& Sulman, 1946; Greenwald, 1956; Austin, 1957; Breed, 1967; Richmond \& Conaway, 1969; Clulow \& Mallory, 1970; Kirkpatrick \& Valentine, 1970), and this type of cycle has been proposed as characteristic of the entire genus (Breed, 1967; Richmond \& Conaway, 1969; Clulow \& Mallory, 1970). In order to examine the generality of this proposal, the reproductive cycle of montane voles, Microtus montanus, was examined under controlled laboratory conditions.

Cross (1972) reported evidence suggesting that induced ovulation occurs in montane voles. Direct comparisons were, however, made only between mated females and unreceptive (presumably non-oestrous) females. Inasmuch as non-oestrous females might not be expected to ovulate even if ovulation were spontaneous, the experiment lacks the necessary control group of unmated, oestrous females. His conclusion is thus premature. The present study was designed to investigate three aspects of the reproductive cycle of $M$. montanus: (1) ovulation, (2) the oestrous cycle since no systematic investigation of the oestrous cycle of montane voles has been reported, and (3) the occurrence of post-partum oestrus.

All voles were reared in the laboratory from a colony maintained at the University of Florida. Animals were housed in plastic tub cages, either $29 \times 19 \times 13$ or $48 \times 27 \times 13 \mathrm{~cm}$. 'San-i-cel' (Paxton Processing Co., Paxton, IIl.) was employed as substrate, and 'Nestlets' (Ancare Corp., Manhasset, 
N.Y.) were provided for nesting material. 'Purina Rabbit Chow' (Ralston Purina Co., St Louis, Mo.) and water were available at all times. The colony was maintained on a reversed 14-hr light/10-hr dark cycle.

In Exp. 1, designed to examine ovulation, twenty-two adult females (aged 4 to 12 months) were employed as subjects with fifteen males used for mating partners. All animals were sexually experienced and of proven fertility. Oestrus was elicited in females by placing them in close proximity to males. Plastic cages $(48 \times 27 \times 13 \mathrm{~cm})$ were divided by a removable, hardware cloth barrier, a male being housed in one half and a female in the other. Vaginal smears were taken daily with a wire loop until females had exhibited two successive oestrous smears (defined as those containing $50 \%$ or more cornified cells).

Mating tests were conducted on the second consecutive day of oestrus during the dark phase of the light cycle. Tests involved one of two experimental conditions: mated or unmated. For the ten mated females, the hardware cloth barrier was removed and the male was allowed access. Copulation was observed only up to the end of the first ejaculation but the pair was allowed to continue copulating for a further $2 \mathrm{hr}$. For the twelve unmated females, the male was removed before elimination of the barrier. No male was employed more than once in either condition; seven served in both conditions.

Females were killed $24 \mathrm{hr}$ after the mating tests. Their ovaries were removed, fixed in formalin, embedded in paraffin wax, sectioned at $10 \mu \mathrm{m}$, and stained with haematoxylin and eosin. Corpora lutea and Graafian follicles were counted and measured using the method of Breed (1969).

Copulation produced ovulation in all females of the mated group, with ovulation defined by the presence of at least one CL. By contrast, only two of the twelve unmated females ovulated. No differences in size or cellular structure were apparent between the CL of mated females and those of unmated, ovulating females. For all ovulating females, the mean number of CL was $5 \cdot 1( \pm$ S.E. 0.93$)$ and the mean CL diameter was $786 \cdot 3 \mu \mathrm{m}$ ( \pm S.E. $57 \cdot 6)$. Two of these females also possessed one follicle in which the ovum lay free in the central cavity encircled by eosinophilic material. In ovulating females, Graafian follicles were rare and those present never exceeded $500 \mu \mathrm{m}$ in diameter. Unmated females showed a predominance of large Graafian follicles from 600 to $800 \mu \mathrm{m}$, with a mean of 5.9 follicles $( \pm$ S.E. $1 \cdot 12)$ in this range.

$M$. montanus showed no evidence of the development of accessory CL, which have been reported for $M$. californicus (Greenwald, 1956), the mean of 5.1 true CL per animal being in line with reported litter sizes for $M$. montanus (Negus \& Pinter, 1965; Colvin \& Colvin, 1970). There was also a lack of any pronounced preovulatory swelling of follicles, the size of CL at $24 \mathrm{hr}$ and of Graafian follicles of oestrous females being very similar. This finding conflicts with that of Cross (1972) for $M$. montanus although similar results have been reported for M. agrestis (Breed \& Clarke, 1970).

In Exp. 2, daily fluctuations in the vaginal epithelium were investigated. Subjects were twenty adult females (aged 4 to 6 months). Females were allotted to four equal experimental groups: (1) virgins housed singly, (2) virgins housed adjacent to males, (3) parous females housed singly, and (4) parous females housed adjacent to males. Housing of females adjacent to males was 
accomplished by the use of the divided tub cage. Daily vaginal lavages with a glass pipette were carried out on all females for 25 days. Lavage smears were stained in $1 \%$ toluidine blue, and the percentages of cornified, nucleated and leucocytic cell types were estimated by careful examination.

The lavages produced no evidence of regular, cyclical changes in the percentages of the three cell types for any female in any of the four groups. Females in all groups characteristically showed a predominance of cornified cells $(50 \%$ or more) for periods of several days alternating with several days of leucocyte invasion. Nucleated cells were rarely dominant. The distribution of oestrous periods (periods of cornified cell predominance) was analysed by calculating the time from the first day of each oestrous period to the first day of the next oestrous period. Oestrous periods initiated before the first lavage or extending beyond the last day's lavage were excluded from the analysis since no definite interval could be obtained. The modal interval for all females was 5 days (range, 2 to 13 days), but this represented less than $30 \%$ of the total intervals. Several females showing periods of oestrus or dioestrus (50\% or more leucocytes) exceeding 15 days are not represented since such periods either began or ended outside the 25-day experiment. Modes of oestrous periodicity for the four experimental groups were 5 days for Group 1 (virgin-isolated), 10 days for Group 2 (virgin-male), 4 days for Group 3 (parousisolated), and 7 days for Group 4 (parous-male). Individual differences were considerable. Five females (one from Group 1, three from Group 2, and one from Group 4) demonstrated a predominance of cornified cells for 20 days or more while leucocytic lavages were obtained from one female (Group 1) throughout the 25-day period. Females housed adjacent to males showed a tendency to more days of cornified cell predominance.

In Exp. 3, the occurrence of post-partum oestrus was investigated. Fifteen fertile breeding pairs were used and after the birth of a litter for each pair, the male was allowed to remain with the female for approximately 30 days. The date of birth for the next litter was noted, and the interval separating the two litters was calculated.

Ten of the fifteen pairs showed between-litter intervals of 21 to 26 days, with four pairs producing a second litter in 21 days and three pairs in 22 days. Only two other pairs produced a second litter, and these had between-litter intervals of 42 and 46 days. Inasmuch as breeding data from our laboratory, as well as published reports (Seidel \& Booth, 1960), indicate a gestation period of approximately 21 days, the demonstration of intervals of 21 to 26 days indicates that conception of the second litter occurred within a few days of parturition. A suppression of oestrus during the remaining days of lactation is suggested by the overall distribution of the second litters.

Induced ovulation is the characteristic pattern of $M$. montanus, copulation dramatically increasing the probability of ovulation in oestrous females. These results support the suggestion of Cross (1972). The stimuli capable of eliciting ovulation show some degree of specificity since neither the vaginal smear procedure nor the presence of a male reliably produced ovulation. Ovulation did occur, however, in the absence of copulation in $17 \%$ of oestrous females and may have been related to environmental stimuli. It is also possible 
that oestrous females may have a low rate of spontaneous ovulation. Ovulation in unmated females has been reported for $M$. pinetorum, which usually exhibits induced ovulation (Kirkpatrick \& Valentine, 1970). Clear-cut distinctions between species exhibiting spontaneous and induced ovulation may be arbitrary (Conaway, 1971). Indeed, ovulation can be modulated by coitus-related stimuli in such spontaneously ovulating species as rats (Zarrow \& Clark, 1968), pigs (Signoret, du Mesnil du Buisson \& Mauléon, 1972) and man (Jochle, 1973).

Results for $M$. montanus add support to the view that induced ovulation and the absence of regular oestrous cycles are general features of the reproductive biology of Microtus. This genus may thus be differentiated from other genera within the Cricetidae in their reproductive cycle (Conaway, 1971). Careful delineation of the reproductive cycles of species within this family would seem to offer a valuable opportunity of examining the adaptive significance of differences in reproductive cycles within a restricted taxonomic group.

The authors wish to thank Mrs Barbara McGuire and the Center for Neurobiological Sciences for assistance in the histological preparation of ovaries. Two of us (G.D.G. and H.N.D.) were supported by Training Grant NIHMH-10320 to the Center for Neurobiological Sciences, University of Florida. This research was supported by Grant GB-33837x from the National Science Foundation.

\section{REFERENCES}

Austin, C. R. (1957) Oestrus and ovulation in the field vole (Microtus agrestis). F. Endocr. 15, iv.

Bodenheimer, F. S. \& Sulman, F. (1946) The oestrous cycle of Microtus guentheri D. and A., and its ecological implications. Ecology, 27, 253.

BREED, W. G. (1967) Ovulation in the genus Microtus. Nature, Lond. 214, 826.

BreEd, W. G. (1969) Oestrus and ovarian histology in the lactating vole (Microtus agrestis). J. Reprod. Fert. 18, 33.

Breed, W. G. \& Clarke, J. R. (1970) Ovulation and associated histological changes in the ovary following coitus in the vole (Microtus agrestis). F. Reprod. Fert. 22, 173.

Clulow, F. V. \& Mallory, F. F. (1970) Oestrus and induced ovulation in the meadow vole, Microtus pennsylvanicus. 7. Reprod. Fert. 23, 341.

Colvin, M. A. \& Colvin, D. V. (1970) Breeding and fecundity of six species of voles (Microtus). $\mathcal{F}$. Mammal. 51, 417.

Conaway, G. H. (1971) Ecological adaptation and mammalian reproduction. Biol. Reprod. 1, 239.

CRoss, P. G. (1972) Observations on the induction of ovulation in Microtus montanus. F. Mammal. 53, 210.

Greenwald, G. S. (1956) The reproductive cycle of the field mouse Microtus californicus. F. Mammal. 37, 213.

Jochle, W. (1973) Coitus-induced ovulation. Contraception, 7, 523.

KirKPatrick, R. L. \& Valentine, G. L. (1970) Reproduction in captive pine voles, Microtus pinetorum. F. Mammal. 51, 779.

Negus, N. G. \& Pinter, A. J. (1965) Litter sizes of Microtus montanus in the laboratory. F. Mammal. 46, 434 .

Richmond, M. \& Conaway, C. H. (1969) Induced ovulation and oestrus in Microtus ochrogaster. $\mathcal{F}$. Reprod. Fert., Suppl. 6, 357.

SEIDEL, D. R. \& Booth, E. S. (1960) Biology and breeding habits of the meadow mouse, Microtus montanus, in eastern Washington. Walla Walla Coll. Publs Dep. biol. Sci. 29, 1.

Signoret, J. P., du Mesnil du Buisson, F. \& Mauléon, P. (1972) Effect of mating on the onset and duration of ovulation in the sow. $\mathcal{F}$. Reprod. Fert. 31, 327.

Zarrow, M. X. \& CLARK, J. H. (1968) Ovulation following vaginal stimulation in a spontaneous ovulator and its implications. F. Endocr. 40,343. ded from Bioscientifica.com at 04/26/2023 05:02:21AM 